\title{
Towards a Conversion of the Nursing Communication Paradigm: A View from the Analysis of Actual Nurse-Elderly Interactions
}

\section{Fukaya $\mathrm{Y}^{1^{*}}$ and Kitamura $\mathrm{T}^{2}$}

${ }^{1}$ Department of Nursing, Kanto-Gakuin University, Japan

${ }^{2}$ School of Law, Tokai University, Japan

*Corresponding author: Yasuko Fukaya, Department of Nursing, Kanto-Gakuin University, Japan, Tel: 819088556969; E-mail: yafukaya@kanto-gakuin.ac.jp

Received date: January 4, 2018; Accepted date: January 17, 2018; Published date: January 24, 2018

Copyright: (c) 2018 Fukaya Y, et al. This is an open-access article distributed under the terms of the Creative Commons Attribution License, which permits unrestricted use, distribution, and reproduction in any medium, provided the original author and source are credited.

\begin{abstract}
We have conducted a series of studies on communication between nurses and elderly patients in geriatric facilities in Japan. The average speech duration per day for elderly people in nursing homes was roughly 4 minutes. The reason for such a short speech duration was that $76 \%$ of the nurses' communication content was composed of "type I" communication ("task-oriented" communication) and that "type II" communication ("life-worldly" communication) made up for only $24 \%$ of the total. We also analyzed the ways in which "type I" communication constrained spontaneous speech by the elderly whereas "type II" communication tended to promote and encourage it. This article, based on the findings obtained from our research, aims to encourage reconsideration and advancement in the research of nursing communication.
\end{abstract}

Keywords: Nursing communication; type I communication; type II communication; Elderly residents

\section{Introduction}

This paper, based on a brief review of the previous literature on nurse-patient communication, introduces the findings obtained from our research and aims to encourage reconsideration of the research and practice of nursing communication.

Communication is the fundamental basis for human sociality through its work of creating and maintaining our social world [1]. In nursing science, the importance of communication is well recognized. For, in order to provide appropriate assistance to meet the healthcare needs of patients at various health levels, the construction of interpersonal relationships with patients is of vital importance.

Furthermore, all nursing activities, such as information collection, the evaluation of patients' problems, nursing decision making, explanations to patients, provision of nursing care, and so on, are all realized and implemented through various kinds of communication in nursing settings. In other words, it may be said that almost all nursing activities entirely depend on communication.

Therefore, the importance of communication between the patient and the nurse in nursing care is recognized and has been repeatedly emphasized in nursing studies. For example, a questionnaire survey conducted in the 1980s on the satisfaction of hospital health care services found that the overwhelming majority of complaints were about communication with health workers, especially nursing staff [2]. The importance of communication in nursing settings is also pointed out repeatedly in recent research after 2000. For example, Vivian and Wilcox showed that patients' perceptions of the quality of communication with nurses were related to patient satisfaction and compliance, resulting in a significant effect on patient outcomes [3]. Despite the importance of the communication between the patient and the nurse being frequently underlined in the previous literature in this way, the numerous problems and challenges that nurses face in the clinical setting have also been reported.

One such problem is a lack in the amount of verbal communication at the nursing site [4-6]. For example, Armstrong-Esther and Browne $[7,8]$ observed that the amount of verbal communication is very small, except for routine nursing activities: in $52 \%$ of nursing encounters with patients, nurses had no interaction with them. Nolan et al. found that while nurses recognized that communication with patients was of utmost priority, the amount of communication in the actual nursing setting was very small [9].

Another problem relates to the quality of nurse-patient communication. Especially with regard to communication between nurses and the elderly, the contents of communication are superficial, elderly utterances are controlled by nurses, one-way (one-sided) conversation is overwhelmingly prevalent, and the use of baby talk (such as how one talks to a child) is frequent [9-12]. In addition, while the above problems and challenges that nurses face in clinical settings have been reported in previous literature, we have also noted some problems with regard to the ways in which the previous studies have been conducted.

First, many of the previous studies have been done through the observation of specific types of care activities, such as dietary assistance, and thus the full extent of the communication in a wide range of different nursing activities has not necessarily been the focus of the studies.

Secondly, overwhelming attention has been paid to the activities and utterances of the nurses, rather than those of patients. That is, although communication is a "mutual act" (namely, an interaction), the contribution of patients to the communication is largely ignored, and as a result, the "process of communication" has been hardly considered in conventional nursing communication studies $[13,14]$.

Against the background of the above-mentioned previous nursing communication research, we have to date conducted, with a view to 
advancing nursing communication research, three stages of research on the communication between caregivers and elderly residents. First, we started by investigating conversation content and time of day by tape recording and transcribing conversations between elderly and facility nursing care staff [15].

Then, based on the findings revealed by this research, we developed an educational intervention program to improve the communication of nurses, and examined its effectiveness [16]. Third, we examined the influence of educational intervention programs on the language of the staff, and clarified the mechanisms of communication between the care providers and the elderly, from the viewpoint of "interaction" with each other $[17,18]$. What follow are some details of the stages of our study.

- The aim of the first research stage was to clarify the actual situation concerning verbal communication between caregivers and elderly residents. The subjects were 37 elderly residents in general hospital recuperation wards and 34 elderly residents in public aid nursing homes. The study method involved analysing the types of verbal communication and utterances by caregivers and the elderly, with the duration and frequency of the communication measured. The observation period lasted from 9:00 am to 5:00 pm. Factors affecting caregiver and elderly resident utterances were then evaluated. In this stage of research, the two types of communication between the two parties were identified: type I (instrumental speech/communication related to staff nursing tasks) and type II (life-worldly speech/communication related to elderly life) [15].

- The second stage research was designed and developed as an education intervention (lecture and group discussion) with the aim of making caregivers aware of the need for Type II communication with the elderly, and to discover practical measures for increasing Type II communication after such education intervention. The subjects were the 240 nurses who had the possibility of being assigned to work with any of the 37 elderly people from the 3 general hospital recuperation wards. The educational intervention in this study comprised of a lecture (30 minutes) on the importance of Type II communication, and a group discussion (60 minutes) based on 'Critical Reflection', for a total of 90 minutes conducted once at each surveyed facility. The group discussions focused on the current state of verbal communication by caregivers, the background to the current communication situation, and improvement measures for increasing Type II communication. In order to evaluate the effect of the educational intervention, measurement of the type and quantity of verbal communication was performed for a full day at each facility before the intervention, 1 week after the intervention, and 3 months after the intervention. The observation period lasted from 9:00 am to 5:00 pm. To assess reproducibility, the measurements were repeated three times [16].

- The aim of the third stage of research was to (a) examine the effect of educational intervention on the frequency and duration of all utterances and self-initiated utterances by elderly residents prior to the educational intervention, and (b) to examine the structural mechanisms of Type II speech through comparing the characteristics of Type I and Type II communication. The subjects of the survey were 37 elderly people in the general hospital recuperation wards of 3 facilities, which were the subject of the second survey. In researching, we used statistical analysis to understand the changes in speech content and duration of elderly residents before and after the educational intervention of nurses.
Conversational analysis was used for analyzing the structural mechanisms of communication $[17,18]$.

Details of the results of the three research stages are as follows. The average speech duration of the elderly patients was $247.4 \mathrm{sec}$ (SD 171.06) in one day, or roughly about 4 minutes. Table 1 shows the speech duration broken down by minutes, with the total duration of speech being less than 5 minutes for $70 \%$ of individuals. For $18.9 \%$ of the individuals, the total duration of speech was less than 1 minutehighlighting the troubling speech situation of elderly residents currently living in geriatric care facilities in Japan, and the situation that we will face when we become older.

\begin{tabular}{|l|l|l|}
\hline Duration & $\mathbf{n}$ & $\%$ \\
\hline Less than 1 min & 7 & 18.92 \\
\hline 1 min-Less than 2 min & 5 & 13.51 \\
\hline 2 min-Less than 3 min & 8 & 21.62 \\
\hline 3 min-Less than 4 min & 5 & 13.51 \\
\hline 4 min-Less than 5 min & 3 & 8.11 \\
\hline 5 min or longer 29.73 & 11 & 29.73 \\
\hline
\end{tabular}

Table 1: Speech duration in 1-min intervals; [Cited from Fukaya et al. (2009)].

Figure 1 shows the amount of time each elderly person was spoken to by the staff per day. The daily mean was 17.26 minutes. The numerical values are expressed in seconds, so the least amount of time that a staff member spoke to an individual was 500 seconds, or approximately 8.3 minutes, and the maximum amount of time was 2250 seconds, or approximately 37.5 minutes. The time that the staff spoke to an individual varied depending on the facility.

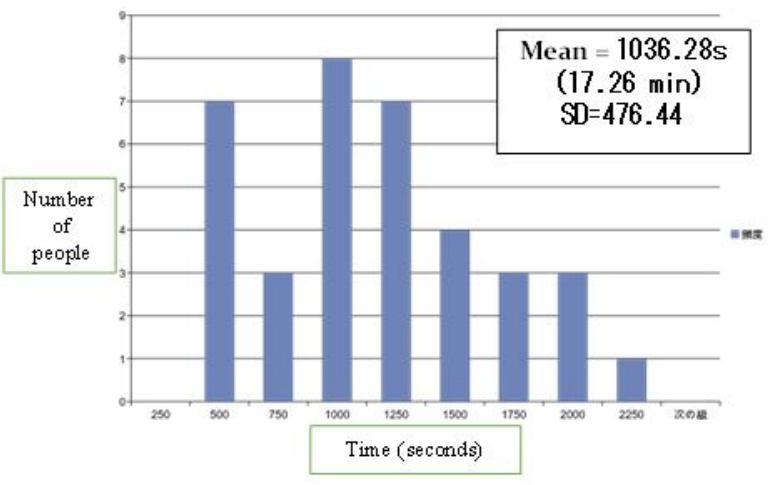

Figure 1: Amount of time that the staff spoke with an elderly individual; [Cited from Fukaya et al. (2004)].

As shown in Table 2, when comparing the time that the staff spoke to individuals in different types of facilities, the mean time was 1084 seconds in general hospital recuperation wards and 1391 seconds in public aid nursing homes, with the latter being significantly higher. Thus, the more medically dependent the elderly people were, the less the staff spoke to them. 


\begin{tabular}{|l|l|l|l|l|l|l|}
\hline $\begin{array}{l}\text { Speech } \\
\text { duration }\end{array}$ & Facility type & $\mathbf{n}$ & $\mathbf{M}$ & SD & $\mathbf{t}$ & $\mathbf{p}$ \\
\hline Caregivers & $\begin{array}{l}\text { Recuperation } \\
\text { ward }\end{array}$ & 37 & 1084.34 & 544.14 & -1.92 & * \\
\cline { 2 - 7 } & $\begin{array}{l}\text { Public aid } \\
\text { nursing home }\end{array}$ & 34 & 1391.44 & 788.91 & - & - \\
\hline \multirow{2}{*}{$\begin{array}{l}\text { Elderly } \\
\text { people }\end{array}$} & $\begin{array}{l}\text { Recuperation } \\
\text { ward }\end{array}$ & 37 & 247.42 & 222.91 & -0.48 & - \\
\cline { 2 - 7 } & $\begin{array}{l}\text { Public aid } \\
\text { nursing home }\end{array}$ & 34 & 275.09 & 262.98 & - & - \\
\hline
\end{tabular}

Note: ${ }^{*}=p<.05$

Table 2: Relation between caregivers' speech duration and elderly speech duration and facility characteristics; [cited from Fukaya et al. (2004)].

Types of communication between caregivers and elderly residents were extracted using content analysis. As shown in Table 3, communication between them was categorized into 2 types. The first type of communication, making up to $76 \%$ of the total, was task oriented communication, which includes talking based on various nursing or caregiving responsibilities to elicit daily living activities from the elderly, labeled here as "type I" communication. The most common type of type I communication, at $44 \%$, was talking to prompt an action from an elderly person, such as "Okay, open your mouth and swallow," or "Grab a hold of that." Next was speech that is always addressed to patients or elderly persons when caregivers are providing some type of care.

\begin{tabular}{|l|l|l|}
\hline Primary Category & Secondary Category & $\%$ \\
\hline \multirow{5}{*}{ Type I (76\%) } & Utterances related promotion of behaviour & 44 \\
\cline { 2 - 3 } & Utterances related assistance behaviour & 23 \\
\cline { 2 - 3 } & $\begin{array}{l}\text { Utterances about physical condition and daily } \\
\text { routine }\end{array}$ & 16 \\
\cline { 2 - 3 } & Confirming wishes and desires & 10 \\
\cline { 2 - 3 } & Warning to be careful & 4 \\
\hline & Other & 3 \\
\hline \multirow{5}{*}{ Type II (24\%) } & Utterances about social events & 30 \\
\hline & $\begin{array}{l}\text { Utterances about psychological state/ } \\
\text { knowledge }\end{array}$ & 29 \\
\hline & Utterances about life experience & 8 \\
\hline & Greetings & 21 \\
\hline & Other & 12 \\
\hline
\end{tabular}

Note: Type I=Task-oriented, Type II=Life-worldly

Table 3: The type of communication; [Cited from Fukaya et al. (2004)].

This is when the staff tells an elderly person what they intend to do, or when they want the elderly person to understand what they are doing, such as, "I'm going to wipe your back a bit," or "Okay, I'm going to push the wheelchair." This type of speech accounted for $23 \%$ of the total. The next type is speech attempting to assess or explain the physical status of the elderly person, such as, "You are a little red here," or "Does this hurt?" Temperature measurement is a good example of this type of speech.

This type of speech made up to $16 \%$ of the total. Another type of type I communication, which consisted of up to $10 \%$ of the total, is speech to confirm the requests or wishes of the elderly individual, such as, "Are you hungry?" or "Is your room too hot?". Warnings to patients made up $4 \%$ such as, "Be careful, the tea is hot," or "There is a step here". Miscellaneous speech made up to $3 \%$.

The second type of communication, labeled here as "type II", was "life-worldly communication", related to conversations about family, work, or social events that occur normally in social interactions. These made up to $24 \%$ of the total. The most common of type II communication, at $30 \%$, was speech related to social events such as newspaper or television news on, for example, elections or sport events. The next most common type II communication, at $29 \%$, was speech for stabilizing the patient's psychological state, such as, "Would you wait a bit for the meal?", and for verifying knowledge, such as "What is this flower?" or "Have you seen this before?". Greetings, such as "Good morning" or "Nice weather, isn't it?" made up $12 \%$ of the total, while speech about life experiences were at $8 \%$. These includes conversations about the elderly person's past job or cooking recipes. Miscellaneous speech made up to $21 \%$ of the total.

With a view to examining what type of interactions occur in type I and type II communication, we used conversation analysis to analyze the actual interactions that occurred between nurses and patients. Conversation analysis is an analytical method based on ethnomethodology. Garfinkel describes ethnomethodology as the study of "the methods" used when various activities or behaviors are performed routinely and naturally by "people (ethno-)" in society to achieve intersubjectivity or social order [19]. Conversation analysis is an attempt to elucidate linguistic interactions, as well as the order and mechanisms of behavior and activities that we perform through those interactions, by studying detailed transcripts from audio/visual recordings [20].

Table 4 shows examples of type I and type II communication when assisting a patient in taking a bath. The characteristics of the interactions in type I communication, as shown in the left part of Table 4, were analyzed from 3 different aspects: (1) characteristics of speech sequence and order assignment, (2) characteristics of conversation content, and (3) characteristics of speech length. All of the caregiver's speaking turns of speech, for example, in lines 1, 3, 5, and 7 were initiated on her own initiative. In contrast, all the utterances of the resident, in lines 2,4 , and 6 are replies to the caregiver.

In other words, they are all produced as the second-pair parts of adjacency pairs prompted by the caregiver's speech. Thus, self-initiated utterances by the resident are entirely absent. With regard to the characteristics of the content of this conversation, as in, "I'll wipe your back a bit" and "Okay? Can you turn to the side?", the speech from the staff is a prompt to the elderly person so that the caregiver can perform a specific work task, such as wiping the individual's back. In most cases, the elderly person then responds by acknowledging the caregiver's speech (line 2, line 15) and in doing what the caregiver asked. 
Citation: Fukaya Y, Kitamura T (2018) Towards a Conversion of the Nursing Communication Paradigm: A View from the Analysis of Actual Nurse-Elderly Interactions. Adv Practice Nurs 3: 145. doi:10.4172/2573-0347.1000145

Page 4 of 8

\begin{tabular}{|c|c|c|c|c|c|}
\hline \multicolumn{3}{|c|}{ Excerpt 1 (Type I) } & \multicolumn{3}{|c|}{ Excerpt 2 (Type II) } \\
\hline 1 & $\mathrm{CP}$ & $\begin{array}{l}\text { Sukoshi senakawo fukimasu. } \\
\text { l'll wipe your back a bit. }\end{array}$ & 1 & $\mathrm{CP} 1$ & $\begin{array}{l}\text { Sato-imo wa mada desu ka? } \\
\text { Taro roots aren't ready yet?= }\end{array}$ \\
\hline 2 & $\mathrm{OP}$ & $\begin{array}{l}\text { Hai. } \\
\text { Yes. }\end{array}$ & 2 & OP & $\begin{array}{l}=\text { korekara desu } \\
=\text { They're just about ready. }\end{array}$ \\
\hline 3 & $\mathrm{CP}$ & $\begin{array}{l}\text { li?Yoko mukemasuka? } \\
\text { OK? Can you turn to the side? }\end{array}$ & 3 & - & $(0.2)$ \\
\hline 4 & $\mathrm{OP}$ & $\begin{array}{l}\text { nn, sonomama ni shite. } \\
\text { No, leave me as I am. }\end{array}$ & 4 & $\mathrm{CP} 1$ & $\begin{array}{l}\text { Un } \\
\text { Yeah }\end{array}$ \\
\hline 5 & $\mathrm{CP}$ & $\begin{array}{l}\text { Hhh. Senaka wo fukimasu-kara, yokowomui-te. } \\
\text { Hhh. I'll wipe your back, so let's turn to the side. }\end{array}$ & 5 & - & $(0.4)$ \\
\hline 6 & $\mathrm{OP}$ & $\begin{array}{l}\text { Uhuh } \\
\text { Uhuh }\end{array}$ & 6 & OP & $\begin{array}{l}\text { Kotoshi wa dekita kana to omotte } \\
\text { I was wondering if they were ready this year }\end{array}$ \\
\hline 7 & $\mathrm{CP}$ & $\begin{array}{l}\text { ii-desuka? Hai. Sokoni tukamatte kudasai. } \\
\text { OK? Yeah. Just hold onto it please. }\end{array}$ & 7 & $\mathrm{CP} 2$ & Huhuhuhu[hu \\
\hline 8 & - & $(0.5)$ & 8 & OP & $\begin{array}{l}\text { [amega yoku futta [kara } \\
\text { [Because a lot of rain [fell. }\end{array}$ \\
\hline 9 & $\mathrm{CP}$ & $\begin{array}{l}\text { Tukamatte. } \\
\text { Ho:Id onto it. }\end{array}$ & 9 & $\mathrm{CP} 2$ & $\begin{array}{l}\text { soudane ame futta monone? } \\
\text { That's right:: There was a lot of rain, wasn't there::? }\end{array}$ \\
\hline 10 & - & $(0.5)$ & 10 & OP & $\begin{array}{l}\text { Uchino musukowa imane, Kinoko-tori ni muchuu= } \\
\text { My son is now engrossed in picking mushrooms= }\end{array}$ \\
\hline 11 & $\mathrm{CP}$ & $\begin{array}{l}\text { Konna funi? } \\
\text { Like this? }\end{array}$ & 11 & $\mathrm{CP} 2$ & $\begin{array}{l}=\text { Ahahahahahaha kinoko ka::? } \\
\text { =Ahahahahahaha mushrooms? Haha:: }\end{array}$ \\
\hline 12 & - & $(10.0)$ & 12 & OP & $\begin{array}{l}\text { Kinoko wo torini }= \\
\text { Going picking mushrooms= }\end{array}$ \\
\hline 13 & $\mathrm{CP}$ & $\begin{array}{l}\text { Dokoka kayu-toko arimasu-ka? Senaka-wa? } \\
\text { Anywhere itchy? On your back? }\end{array}$ & 13 & $\mathrm{CP} 2$ & $\begin{array}{l}=a a \text { sounano? Mou osoinn-jya naino? } \\
=\text { Is that so? Isn't it too late? }\end{array}$ \\
\hline 14 & - & (2.5) & 14 & OP & $\begin{array}{l}\text { Nani? } \\
\text { What? }\end{array}$ \\
\hline 15 & $\mathrm{CP}$ & $\begin{array}{l}\text { Dokomo? } \\
\text { Nowhe:re? }\end{array}$ & 15 & CP1 & $\begin{array}{l}\text { Ima jikinano? (0.3) mou osoinn-jya naino? } \\
\text { Is it the season now? (0.3) Is it just right? Now? }\end{array}$ \\
\hline 16 & $\mathrm{OP}$ & $\begin{array}{l}\text { Ee. Ano: } \\
\text { No. Well: }\end{array}$ & 16 & OP & $\begin{array}{l}\text { Ima, chodo-ii jikidesu. } \\
\text { Now is just the right time. }\end{array}$ \\
\hline 17 & $\mathrm{CP}$ & $\begin{array}{l}\text { Hai? } \\
\text { Yes? }\end{array}$ & 17 & $\mathrm{CP} 1$ & $\begin{array}{l}\text { Nn: (0.8) hahaha } \\
\text { Mm: (0.8) hahaha }\end{array}$ \\
\hline 18 & - & $(1.2)$ & 18 & OP & $\begin{array}{l}\text { Kama wo oite kichattande, } \\
\text { He left the little sickle when he came, }\end{array}$ \\
\hline 19 & $\mathrm{CP}$ & $\begin{array}{l}\text { Omutu-no mawari wa? Sokowa daijyoubu desuka? } \\
\text { What about around your diaper? Are you OK around } \\
\text { there? }\end{array}$ & 19 & $\mathrm{CP} 1$ & $\begin{array}{l}E ? \\
\text { What? }\end{array}$ \\
\hline 20 & $\mathrm{OP}$ & $\begin{array}{l}\text { Hai. } \\
\text { Yes. }\end{array}$ & 20 & OP & $\begin{array}{l}\text { Kama wo ne. } \\
\text { The little sickle. }\end{array}$ \\
\hline
\end{tabular}




\begin{tabular}{|l|l|l|l|l|l|}
\hline 21 & - & $((5$ lines omitted $))$ & 21 & CP1 & $\begin{array}{l}\text { Nn: } \\
\text { Mm: }\end{array}$ \\
\hline 22 & - & $(8.0)$ & 22 & OP & $\begin{array}{l}\text { Kamawo ne, yamani oiteccha-tten desu. } \\
\text { The little sickle, he left it on the mountain. }\end{array}$ \\
\hline 23 & CP & $\begin{array}{l}\text { OK, owari-mashita. Hai, saa iidesuyo. } \\
\text { OK, finished. Yes, it's OK. Please let go. }\end{array}$ & 23 & CP1 & $\begin{array}{l}\text { Nn: (2.0) kinoko ni kuwashii-in desukaka, musuko-san wa? } \\
\text { Ah: (2.0) He's knowlegeable about mushrooms is he, your son? }\end{array}$ \\
\hline & 24 & OP & $\begin{array}{l}\text { Hon wo katte yonnderu no. } \\
\text { He's reading a book he bought about it. }\end{array}$ \\
\hline Note: CP:Care Provider; OP:Older Person & 25 & CP1 & $\begin{array}{l}\text { Ah: sou:?(0.4) hee: } \\
\text { Is that so:? (0.4)Wow: }\end{array}$ \\
\hline
\end{tabular}

Table 4: Examples of Type I and II communication; [Cited from Fukaya et al. (2016)].

From the above analysis, the characteristics of type I communication is as follows: The caregiver obtains information from the patient in relation to the caregiver's task, and therefore, the purpose of this communication is to enable the caregiver to perform his or her task. Since the caregiver requests cooperation from the patient by bringing up a conversation topic with the use of closed questions and leads the conversation, the elderly person's speaking is limited to short utterances, and his or her spontaneous speech is not observed.

The right part of Table 4 is an excerpt of type II communication. In this case, the elderly person had been working in agriculture for many years. First, the staff begins the conversation with "The taro roots aren't ready yet?" The elderly person replies, "They're just about ready." However, in line 4, the staff replies with a "Yeah," and since the next turn to speak has not been taken, the elderly person spontaneously begins speaking with "I was wondering if they were ready this year." Then, the elderly person is able to lead the conversation: "Because a lot of rain fell", "my son is now engrossed in picking mushrooms," and "Going picking mushrooms."

In this way, the staff treats the elderly person as a storyteller by providing a topic related to the life of the elderly person, the topic of taro roots, and by receiving the elderly person's speech with interest by laughing and agreeing, "That's right:: There was a lot of rain, wasn't there::?", and "Ahahahahahaha mushrooms? Haha::".

The characteristics of type II communication are the following: presenting the elderly person with a topic that relates to their own lifeworld can expand the opportunities for the elderly person to speak and, by showing interests and agreement, expand the elderly's speech into an expanded narrative, resulting in prompting the elderly person to speak spontaneously. The results obtained from the conversation analysis were also verified using statistical analysis.
As shown in Figure 2, the relationship between the caregiver's type I speech duration and elderly utterance duration was $r=0.44$, but the relation between the caregiver's type II speech duration and elderly utterance duration was $r=0.58$. Therefore, Type II speech is better at encouraging an elderly person to speak. Thus, it was found that type II communication could promote elderly speech more than type 1 communication. To this end, we conducted an educational intervention aimed at increasing type II communication amongst caregivers.

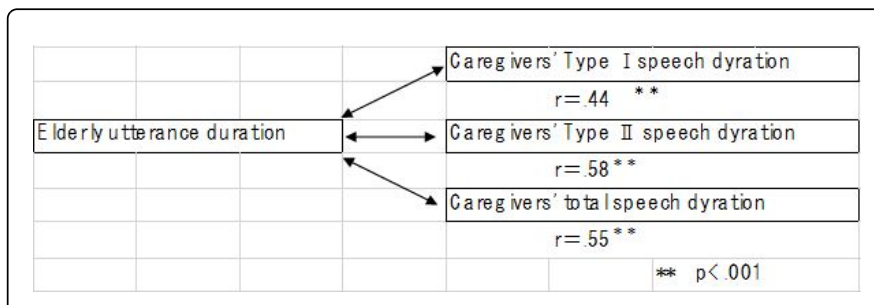

Figure 2: Relation between staff speech duration and elderly utterance duration; [Cited from Fukaya et al. (2004)].

Table 5 shows a comparison of type II communication before and after the intervention to examine its effects. The results showed that the amount of time in type I speech significantly decreased in the 3 months following the intervention compared to the amount of time prior to the intervention. In contrast, the amount of time in type II speech significantly increased 1 week after the intervention to 390.1 seconds, compared to 226.5 seconds prior to the intervention. While type II speech slightly decreased after 3 months, it was still higher than it had been, and therefore we concluded that educating the staff significantly increased type II communication.

\begin{tabular}{|l|l|l|l|}
\hline Caregiver talking & Intervation & Mean Duration (Sec) \pm SD & F-value \\
\hline \multirow{3}{*}{ Total talking duration } & before intervention & $1110.6 \pm 486.0$ \\
\cline { 2 - 4 } & one week after intervention & $1171.6 \pm 616.8$ \\
\cline { 2 - 3 } & 3 months after intervention & $1004.0 \pm 696.9$ \\
\hline
\end{tabular}


Citation: Fukaya Y, Kitamura T (2018) Towards a Conversion of the Nursing Communication Paradigm: A View from the Analysis of Actual Nurse-Elderly Interactions. Adv Practice Nurs 3: 145. doi:10.4172/2573-0347.1000145

Page 6 of 8

\begin{tabular}{|c|c|c|c|c|}
\hline \multirow{3}{*}{ Type I } & before intervention & $882.0 \pm 415.4$ & \multirow{3}{*}{$3.90^{*}$} & \multirow{3}{*}{ * } \\
\hline & one week after intervention & $788.8 \pm 402.8$ & & \\
\hline & 3 months after intervention & $652.3 \pm 387.2$ & & \\
\hline \multirow{3}{*}{ Type II } & before intervention & $226.5 \pm 126.5$ & \multirow{3}{*}{$3.70^{*}$} & \multirow{3}{*}{ * } \\
\hline & one week after intervention & $390.1 \pm 274.0$ & & \\
\hline & 3 months after intervention & $368.5 \pm 430.4$ & & \\
\hline
\end{tabular}

Table 5: Caregiver talking duration before and after educational intervention in two facilities ( $\mathrm{n}=23$ ); [Cited from Fukaya et al. (2009) [16]].

Table 6 shows the effect of educational interventions on the duration an approximate 2 -fold increase in Type II speech time and production and frequency of elderly utterances. The total amount of time that frequency was observed. Therefore, the educational intervention was elderly people spoke increased to a mean of 304.41 seconds from believed to have been effective in increasing the time the staff spoke to 208.23 seconds, but a significant difference was not observed. However, the elderly and in the amount speech from elderly persons.

\begin{tabular}{|c|c|c|c|c|c|c|c|c|}
\hline Elderly utterances & interventions & $\mathbf{n}$ & $\mathbf{M}$ & SD & LL & UL & $\mathbf{t}$ & $\mathbf{p}$ \\
\hline \multirow[b]{2}{*}{ Utterances duration } & Before & 22 & 212 & 185.71 & \multirow{2}{*}{-186.76} & \multirow{2}{*}{12.4} & \multirow{2}{*}{-1.82} & \multirow{2}{*}{0.08} \\
\hline & After & 22 & 299.18 & 259.1 & & & & \\
\hline \multirow[b]{2}{*}{ Type I } & Before & 22 & 155.41 & 146.56 & \multirow{2}{*}{-105.86} & \multirow{2}{*}{35.41} & \multirow{2}{*}{-1.04} & \multirow{2}{*}{0.31} \\
\hline & After & 22 & 190.64 & 168.23 & & & & \\
\hline \multirow[b]{2}{*}{ Type II } & Before & 22 & 56.59 & 54.98 & \multirow{2}{*}{-98.64} & \multirow{2}{*}{5.31} & \multirow{2}{*}{-2.32} & \multirow{2}{*}{0.03} \\
\hline & After & 22 & 108.57 & 122.46 & & & & \\
\hline \multirow[b]{2}{*}{ Utterances frequency } & Before & 22 & 78.23 & 50.84 & \multirow{2}{*}{-36.47} & \multirow{2}{*}{2.65} & \multirow{2}{*}{-1.8} & \multirow{2}{*}{0.09} \\
\hline & After & 22 & 95.14 & 67.48 & & & & \\
\hline \multirow[b]{2}{*}{ Type I } & Before & 22 & 66 & 45.63 & \multirow{2}{*}{-21.82} & \multirow{2}{*}{12.73} & \multirow{2}{*}{-0.55} & \multirow{2}{*}{0.59} \\
\hline & After & 22 & 70.55 & 51.88 & & & & \\
\hline \multirow[b]{2}{*}{ Type II } & Before & 22 & 12.23 & 11.24 & \multirow{2}{*}{-22.03} & \multirow{2}{*}{-2.7} & \multirow{2}{*}{-2.66} & \multirow{2}{*}{0.02} \\
\hline & After & 22 & 24.59 & 24.39 & & & & \\
\hline
\end{tabular}

Table 6: Effect of educational intervention on the duration and frequency of elderly utterances; [Cited from Kitamura et al. (2011) [17]].

Finally, we examined the reasons behind why Type I communication was the main form of speech in actual nursing practice. Table 7 shows some reasons for this. As a result of the content analysis, 3 such factors were identified. The first is the high burden of work and the unrelenting work environment; the second is the lack of awareness and skills towards Type II communication; and the third is, most importantly in relation to this article, that Type II communication is not taken seriously as an integral and constitutive part of nursing per se.

\begin{tabular}{|l|l|}
\hline Primary Category & Secondary category \\
\hline \multirow{3}{*}{ Unrelenting work environment } & Too much work to do \\
\cline { 2 - 2 } & Feeling concerned about colleagues in short-staffed facilities \\
\cline { 2 - 2 } & Work is performed according to role so performing work in one's area of responsibility is prioritized \\
\hline Awareness/skills for Type II Communication & Type II communication is not considered work \\
\hline
\end{tabular}




\begin{tabular}{|l|l|}
\hline \multirow{3}{*}{ Selective speaking to the elderly person } & Engaging in Type II communication appears as if skipping work \\
\cline { 2 - 2 } & Nothing in common with the elderly person to talk about \\
\cline { 2 - 3 } & Lack of interest in the elderly person \\
\hline & If the person is independent, it is OK to speak to him or her only when required. \\
\cline { 2 - 3 } & A person who sees his or her family frequently does not need people to talk to him or her. \\
\cline { 2 - 3 } & Give up on speaking to people that cannot communicate \\
\hline
\end{tabular}

Table 7: Analysis of the current state of speech from the staff*; [Cited from Fukaya et al. (2009) [16]].

\section{Conclusion}

It has been found from our research that communication between the nurses and the elderly is centered on type I communication, as described above, and it is also clear that type II communication is not regarded as a part of nursing work [21]. The reasons why type II communication is not perceived as a constitutive part of nursing work were reported elsewhere [21] and are outlined below. The first reason lies in how communication has so far been perceived in the field of nursing science. This has been described in detail by Peplau and Travelbee, two nursing theorists who have had much influence on the way in which communication in nursing fields is understood.

Peplau once stated that "the purpose of a nurse-patient relationship is different from that of a doctor-patient relationship, friendship, or peer relationship" [22], and Travelbee has written that "the goal of communication in nursing is to confirm and satisfy the nursing needs of sick people" [23]. Moore and Kuipers have also stated that "the nature of the relationship between medical staff and patients is different from that between patients and their relatives in that the former is, by definition, therapeutic" [24].

Thus, perspectives such as these have spread widely, creating a taken-for-granted perspective towards nurse-patient communication. In short, previous communication research has overwhelmingly focused on the medical needs and nursing needs of patients, and as a result communication in a nursing has been understood as merely for therapeutic purposes, that is, as a means of resolving medical or nursing problems and issues, and concurrently, the purpose of their communication tends to be understood narrowly as satisfying the needs of sick people.

Furthermore, this tendency also seems to apply to the currently prevalent conceptions of person (patient)-centered medicine. Person(patient)-centered communication is generally thought of as communication that guarantees that the patient is placed at the center of care and that their wishes and decisions are respected. It is a reaction to, or critique of, the previous principle of centralized treatment [25-28]. Therapeutic communication, which is primarily studied in the field of nursing, is communication aimed at helping a patient conquer personal emotional experiences such as stress or anxiety [29-31]. When understanding communication according to these conceptions, the purpose of communication is to satisfy health needs, medical needs, and physiological and safety needs, and therefore communication is assumed to be only a means of achieving such goals (Figure 3).

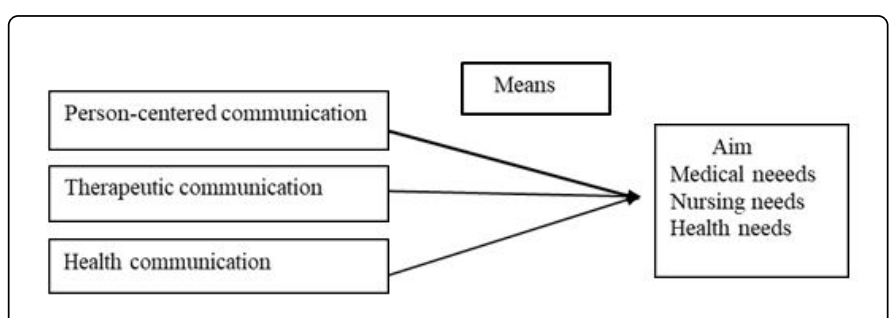

Figure 3: Traditional paradigm of nursing communication studies.

However, we believe that a way of communication that takes into consideration the inherent meaning communication holds for human needs should be explored when examining nursing communication for the elderly, especially for those who have no choice but to live in institutions for a prolonged period and for those in the final stages of life. Figure 4, shows a diagram of Maslow's hierarchy of needs, and is something which all nurses are familiar with [32].

From our research findings, the needs that a nurse emphasizes with type I communication are the physiological and safety needs, while type II communication corresponds to the higher-order needs of belonging, esteem, and self-actualization. The fact that approximately $80 \%$ of nursing communication is that of type I may suggest that nurses are not completely responding to the social needs that patients have as human beings, with nurses being unable to depart from the medical treatment model. Person-centered communication and therapeutic communication are believed to be very important for preventing disease and restoring health.

However, for elderly persons, residents of long-term facilities, patients with end-stage disease, and pediatric patients, communication that further enriches an individual's social life as a human being must be taken into serious consideration. A lack of such types of communication can cause a decline in the sense of person as a social being as well as mental and physiological functions, particularly in elderly people. Nursing, therefore, should provide living support based on a broader definition of health and nursing as physical, emotional, and social well-being.

We believe that it is necessary to convert the purpose of communication into health support in a broader sense, as evident from WHO's definition of health ("Health is a state of complete physical, mental and social well-being and not merely the absence of disease or infirmity") [33]. 


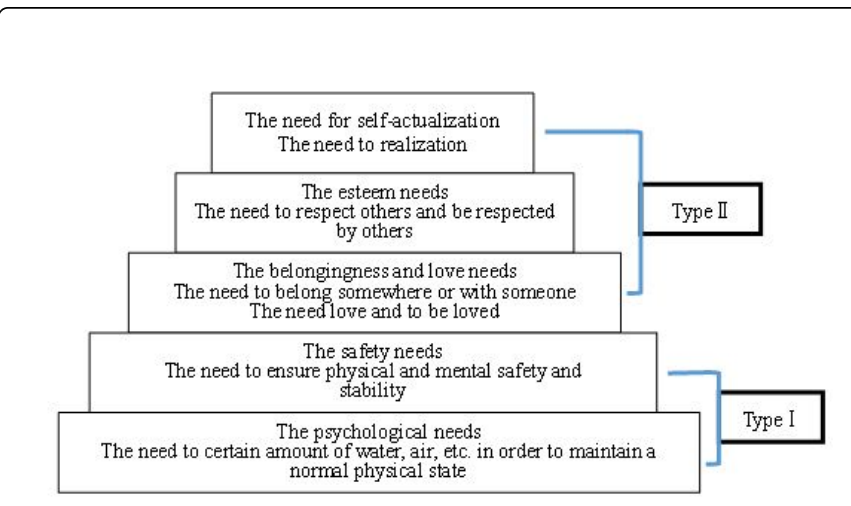

Figure 4: Maslow's hierarchy of needs and communication.

In order to enrich the remaining days of the elderly and of people in the final stage of their life, it is of utmost importance to offer them opportunities to engage in communication that enables these people to lead a normal daily life as a social, autonomous being. In short, communication is important not only as a means of satisfying narrowly conceived nursing needs, but also as a means of satisfying the social needs of patients as human being with dignity.

\section{References}

1. Enfield NJ (2013) Relationship Thinking: Agency, Enchrony, and Human Sociality. Oxford University Press.

2. Clark MJ (1985) The development of research in interpersonal skills in nursing. In Interpersonal Skills in Nursing (Kagan C. ed.) Croom Helm, Dover, New Hampshire pp: 9-21.

3. Vivian BG, Wilcox JR (2000) Compliance communication in home health care: A mutually reciprocal process. Qual Health Res 10: 103-116.

4. Nussbaum JF (1993) The Communicative impact of institutionalization for the elderly: The admissions process. J Aging Studies 7: 237-246.

5. Liukkonen A (1995) Life in a nursing home for the frail elderly: Daily routines. Clin Nurs Res 4: 359-373.

6. Burgio LD, Allen-Burge R, Roth DL, Bourgeois MS, Dijkstra K, et al. (2001) Come talk with me: Improving communication between nursing assistants and nursing home residents during care routines. Gerontologist 41: 449-460.

7. Armstrong-Esther CA, Browne KD (1986) The influence of elderly patients' mental impairment on nurse-patient interaction. J Adv Nurs 11: 379-387.

8. Armstrong-Esther CA, Sandilands ML, Miller D (1989) Attitudes and behaviors of nurses towards the elderly in an acute care setting. J Adv Nurs 14: 34-41.

9. Nolan M, Grant G, Nolan J (1995) Busy doing nothing: Activity and interaction levels amongst differing populations of elderly patients. J Adv Nurs 22: 528-538.

10. Hewison A (1995) Nurses' power in interactions with patients. J Adv Nurs 21: 75-82.

11. Gibb H, O'Brien B (1990) Jokes and reassurances are not enough: Ways in which nurses relate though conversation with elderly clients. J Adv Nurs 15: 1389-1401.
12. Nussbaum JF (1991) Communication, language and the institutionalized elderly. Aging and Society 11: 149-165.

13. Caris-Verhallen WM, Kerkstra A, Mensing JM (1997) The role of communication in nursing care for elderly people: A review of the literature. J Adv Nurs 25: 915-933.

14. Fleischer S, Berg A, Zimmermann M, Wuste K, Behrens J (2009) Nursepatient interaction and communication: A systematic literature review. J Pub Health 17: 339-353.

15. Fukaya Y, Suzuki K, Shichita K (2004) Predictors and correlates of the frequency and the Length of Verbal communications between nursing staff and elderly residents in geriatric care facilities. Japan J Nurs Sci 1: 107-115.

16. Fukaya Y, Koyama S, Kimura Y, Kitamura T (2009) Education to promote verbal communication by caregivers in geriatric care facilities. Japan $\mathrm{J}$ Nurs Sci 6: 91-103.

17. Kitamura T, Fukaya Y, Koyama S, Kimura Y, Nakatugawa J (2011) Change in speaking time of elderly people who require facility care when social communication from staff increased in Japan. USM Int Confer 51-57.

18. Fukaya Y, Kitamura T, Koyama S, Yamakuma K, Sato S (2016) Analysis of utterances by older persons in 'life-worldly' communication with caregivers in Japan. J Nurs Care 5: 5.

19. Garfinkel H (1967) Studies in Ethnomethodology. Englewood Cliffs, Prentice Hall, New Jersey.

20. Sidnell J, Stivers T (2012) The Handbook of Conversation Analysis, John Wiley and Sons.

21. Fukaya Y (2017) Conversion of the communication paradigm for people at the end of their life. Palliat Med Care 4: 1-3.

22. Peplau HE (1952) Interpersonal Relations in Nursing.

23. Travelbee J (1971) Interpersonal Aspects of Nursing (2nd edn) F.A. Davis Company, Philadelphia.

24. Moore E, Kuipers L (1992) Behavioral correlates of expressed emotion in staff-patient interactions. Soc Psychiatry Psychiatr Epidemiol 27: 298-303.

25. Department of Health (2001) National service framework for older people. Standard two: Person-centered care pp: 23-40.

26. Institute of Medicine (2001) Crossing the Quality Chasm: A New Health System for the 21st Century. Committee on Quality of Health Care in America. National Academies Press, Washington (DC).

27. Epstein RM, Franks P, Fiscella K, Shields CG, Meldrum SC, et al. (2005) Measuring patient-centered communication in patient-physician consultations: Theoretical and practical issues. Soc Sci Med 61: 1516-1528.

28. Barnsteiner JH, Disch J, Walton MK (2014) Person and family centered care, overview and history of person-and family-centered care, In sigma Thera Tau International USA.

29. Tan JXJ (2009) The use of effective therapeutic communication skills in nursing practice. Singapore Nurs J 36: 35-40.

30. Leef BL, Hallas D (2013) The sensitivity training clown workshop: Enhancing therapeutic communication skills in nursing students. Nurs Educ Perspect 34: 260-264

31. Sherko E, Eugjen S, Erinda L (2013) Therapeutic communication. Eur J Bioethics 4: 457-466.

32. Maslow A (1954) Motivation and Personality. Harper and Rows, New York.

33. WHO (1946) Constitution of the World Health Organization: Principles. 